\title{
Analysis on New Teaching Models in the Internet Environment
}

\author{
Hongling Guo
}

Public Administration and Law School, Southwest Jiaotong University, Chengdu, China,.610031.

hlg@swjtu.edu.cn

\section{Keywords: MOOC; SPOC; FC; Internet Environment}

\begin{abstract}
New teaching modes in the internet environment have been gaining attention from Academy by the disruptive innovation with which technology is brought into the higher educational system. How to take advantage of these new teaching modes in classroom teaching has become a hot topic of education reform in recent years. In this paper, the author reviewed the existing academic literature and insist these new teaching models have their own characteristics and complement each other. It is important to rationally analyze the advantages and disadvantages of these teaching modes and integrate them to meet teaching needs.
\end{abstract}

\section{Introduction}

With the rapid growth of information technology, some new based-internet teaching models such as MOOC(massive open online courses), SPOC(Small Private Online Course, FC (Flipped Classroom) are booming. They have a great impact on the traditional classroom teaching mode. How to rationally understand the advantages and disadvantages of these new teaching modes and make full use of these advantages has become a hot topic of education reform in recent years. In this paper, several new teaching modes in the internet environment are analyzed, and some suggestions on integration them are put forward.

\section{MOOC and Its Shortcoming}

MOOCs is the English abbreviation of Massive Open Online Courses. MOOCs use the Internet to allow a massive number of students from any age or background to join a course, and study it at any their own pace and time. The term MOOC was first used when George Siemens and Stephen Downes gave online access to their course "Connectivism and Connective Knowledge" in 2008[1]. MOOCs were popularized by the Coursera, Edx and Udacity in 2011 and have attracted much attention because of its free, open and quality. MOOCWATCH reported that 437 universities and colleges in the world are offering 2800+ MOOCs in their 2015 vision report. [2] MOOCs are based on a collection of learning modules given by top educators from highly respected institutions play an important role in realizing the equalization of high-quality education resources. Someone reported that MOOCs could bring disruption to higher education and some lesser-known educational institutions will go out of business because of them. [3]

All this has not happened as was originally predicted yet because some obvious shortcomings are emerging with the growth of MOOCs.

Firstly, teaching forms of courses in MOOCs is single, usually only use the method of lecture. There are no interaction between teachers and students and collective learning mechanisms because the MOOC is pre-recorded. [4]

Secondly, there are high drop-out rates and low completion rates because the quality of learning is not guaranteed without traditional classroom constraints. [5]

Thirdly, the teacher in the MOOC put much attention to knowledge and neglect the cultivation of ability.[6]

Fourth, it is difficult to assess the learning effect of students in the MOOC, which result in that education certification is difficult. [7] 


\section{SPOC and Its Spread}

Professor Armando Fox and David Patterson in University of California at Berkeley put forward "Small Private Online Course" or SPOC to solve the problem of MOOC in 2013. They provided content of the MOOC, called "Cloud computing and software engineering", and related materials to the students in UC Berkeley, and asked them to learn before class. In the class, teachers guide the students to apply the knowledge to solve the real problems in the real world. The mode witch combined MOOC with the traditional classroom teaching provides professional and personalized education to the students. It can be simply expressed as "SPOC=MOOC+ classroom [8]. The MOOC-based blended learning mode breaks the dull atmosphere of passive learning of students in traditional classroom. The students got complete and profound learning experience in their class, which has great advantages in stimulating students' interest and enthusiasm in learning. And this mode can make full use of MOOC resources and the advantages of traditional classroom to improve the quality of learning and teaching [9].

However, SPOC need the teachers to do many works before class such as understanding students' learning needs, formulating learning plans and evaluation strategies, preparing MOOC-based learning materials.[10]And in the process of implementing SPOC teaching, teachers have to think how to reorganizate learning content according to MOOC materials, how to effectively control and supervise the learning process of students; how to provide personalized guidance for each participating student, how to combine theoretical knowledge with reality ; how to build an information-based learning support system for students and so on.[11]

In 2014, SPOC was implemented in the course "cloud computing and software engineering" in Tsinghua university. Then it was promoted to other courses such as "circuit principle", "data structure", "history of Chinese architecture" and other university in China.

It can be seen from the existing literature that there are still the following outstanding problems in the practice of SPOC in China. At First, the teachers, even in some practical courses still pays more attention to knowledge what the students should learn and pays less attention to promote students' ability, especially their ability to apply knowledge. [12] The teaching process is arranged around the understanding knowledge, and the teaching methods mainly serve the mastery of knowledge. At second, there are less cooperations between teachers. Generally, teachers in most of courses independently use network resources, and there are few teaching teams involved. [13]At third, the curriculum design focus on teaching form and ignored the student's real demand.[14] We hardly find survey on students' learning demand before class in the existing SPOC course design . At fourth, the students' academic evaluation standard and methods are still old. Exams and tests are main assessment methods of academic performance. Some courses asked students to submit course summary reports. There are few methods to assess the students'ability to apply theory to reality. From the practice of professor armando, the founder of SPOC, the key factor SPOC succeed is that "students communicate with users and complete real application development", that is actually students ' practical learning experience. However, it is difficult to find such practice in the exploration of SPOC in China.

\section{Experiencing Teaching and Flipped Classroom}

Experiencing teaching is a kind of teaching method based on constructivism theory. It is a student-centered and task-based teaching approach from which students can deeply understand knowledge through their own experiences. [15] Educational psychologists insist that learning is "the process of creating knowledge through experience transformation. Knowledge comes from the acquisition of experience and the synthesis of the transformation process."[16] The history of experiencing teaching is much older than MOOCs, SPOC. The idea of learning knowledge through experience exists in the ancient Chinese education theory. [17] However, as a method of classroom teaching, it was put forward by Bruner based on theory of "cognitive discovery" in the mid-1960s. Experiencing teaching has changed the traditional teacher-centered teaching model. It integrates knowledge imparting, ability training and quality improvement and shorten the gap between theory and reality. It is significance to cultivate students' social adaptability and innovation ability. In the 1990s, 
experiencing teaching were highly regarded in the United States, Japan and France. And in 1999, the basic education curriculum reform in China also emphasized experiencing teaching. [18] The findings from existing research literatures show that experiencing teaching in China mainly focuses on improving students' interest in learning and deepening their understanding of knowledge through case studies or some role-playing activities in class. It is far from helping students to construct knowledge and significance, to improve their mental model and ability. For most of teachers, it is also difficult to obtain resources experiencing teaching needed and real situation except that they could spend a lot of time reorganizing and redesigning course content according to the need of students.

The MOOC-based experiencing teaching in colleges and universities often combines with the flipped classroom in recent years. Flipped Classroom is a problem-oriented teaching form, which base on modern information technology means. [19]

The idea for the flipped classroom was first proposed by Maureen J. Lage and Glenn J. Platt in the business school in Miami University in 1996. Wesley J. Baker thought Model of Flipped Classroom turns knowledge imparting and learning in the traditional classroom to before class by technical means such as micro-video and online homework, and the process of knowledge internalization after class was moved to the classroom. Model of Flipped Classroom leaves more time for interaction and in-depth cooperation among students and between students and teachers in class. [20] Baker insisted Flipped Classroom greatly changed the position, function and importance of the teacher in the classroom [21]. Flipped classroom has been gradually popularized in the United States after 2007. Many courses have been carried out similar teaching reform experiments in the Universities. In 2008, the teaching reform programs in Pennsylvania state university and California state university in the United States were almost all Flipped Classroom practices and got a series of results. In China, Flipped Classroom didn't appear until 2012.So far, Flipped Classroom has been applied in the teaching of English, computer, economics and other courses with more practical activities in some universities. Flipped classroom realizes the comprehensive reconstruction and profound reform of the traditional classroom structure through the activities of students. And it is becoming a display platform to link new theory such as personalized learning, constructive learning and cooperative learning of modern education with classroom teaching practice[22]. But in practice, promoting Flipped Classroom is confronting some challenge in China. Firstly, the production cost of micro video which Flapped Classroom needed is large, and it is difficult for teachers to flip a course by themselves without other support. Secondly, I $t$ is also challenge for the teachers how to propose the online homework or questions to help students systematically construct their knowledge and deepen their understanding. Thirdly, the teachers have to think how to build an effective learning environment according to the needs of students to help them active learning and how to supervise them extracurricular study. Fourthly, how to combine learning knowledge with training ability.

\section{Conclusion}

In summary, it can be found that every new teaching mode in the Internet environment has its characteristics and can complement each other. MOOCs is an open, free and high-quality online resource. It provides a ubiquitous learning environment and the possibility of independent learning to learners. Its deficiencies, such as single teaching form and lack of interactivity, can be made up by SPOC. And MOOCs provide quality teaching resources to SPOC. Flipped Classroom can combine online resources from MOOCs with offline face-to-face teaching in SPOC. Experiencing teaching enriches the teaching form of Flipped Classroom and enhances its function in improving students' quality and ability. The integration of the above teaching modes is great significance in stimulating students' initiative and enthusiasm in learning and improving the quality of classroom teaching. These new modes can even redefine the role of teachers and the social position of universities under the internet environment in future. 


\section{Acknowledgements}

This paper is based on work supported by the Teaching Reform Foundation in Southwest Jiaotong University.

\section{References}

[1] A. M. Mutawa, It is time to MOOC and SPOC in the Gulf Region; Education Technology (2017) 22:1651-1671.

[2] Chung, C. (2015). MOOC vision refinement for 2015. Retrieved from https://docsend.com/view/w28pymq.

[3] Glenda Morgan, J.-M. L. (2015). Three ways MOOCs have changed higher education. (G00275802). Gartner.

[4] Harris, M. (2013). Higher education must prepare for the growing influence of MOOCs (G00249123).

[5][6] T. Xu, A review of the controversial studies behind MOOCs[J] China University Teaching ,2015(7), 22-27,(in Chinese)

[7] Z.t. Zhu, M.z. Liu. New Trends of Online Learning in the Post-MOOC Era[J]. Open Education Research, 2014, (3):36-43. (In Chinese)

[8] [9]Y.Q. Kang,An Analysis on SPOC:Post-MOOC Era of Online Education [J]. Tsinghua Journal of Education,2014,01:85-93. (In Chinese)

[10]]R. Chen,Ch. Yang. Blended Learning for SPOC,[J]. Distance Education in China, 2015,05:42-47+67+80. (In Chinese)

[11] B. He,Y.Chao. SPOC: MOOC-based Innovation of Teaching Processes [J]. China Educational Technology,2015,03:22-29. (In Chinese)

[12]J.T. Luo, X.Q. Gu. The Innovation Research of MOOC from the Perspective of Blended Learning: Case Study of SPOC[J]. Modern Educational Technology, 2014,(7):18-25. (In Chinese)

[13]F.X. Bai, X.Y. Guo and Y. Lin. A study of apply the teaching mode of SPOC into college curriculums [J]. Journal of Yunnan University(Natural Sciences Edition),2014,S2:146-149. (In Chinese)

[14] J. Zhao. Application of SPOC in political theory teaching in the university [J]. Education Exploration, 2015,09:139-142. (In Chinese)

[15] [17]J.H. Zhang,L.Ye, A review of experencing teaching studies[J].Heilongjiang Researches on Higher Education 2010.(6).143-147 . (In Chinese)

[16]Ch. Wang, Exploration and Practice of Project Experience Type Teaching in Information Technology Courses [J].Journal of Shanxi Finance and Economics University, 2013(3),65-71. (In Chinese)

[18] Y.M Hu. Student oriented:Explore the reform of undergraduate talent training in experiencing teaching [J]. China Higher Education,2011,18:38-39. (In Chinese)

[19][20]L.L Lu, Flipped classroom: Traditional classrooms confronting challenges and changing paths[J].University Education Science 2014(6), 66-70.(In Chinese)

[21] J. W. Baker. The Classroom Flip: Using Web Course Management Tools to Become the Guide by the Side $[\mathrm{C}] / / \mathrm{J}$. A. Chambers (Ed.). Selected papers from the 11th International Conference on College Teaching and Learning. Florida US: Florida Community College at Jacksonville , 2000 : 9 17.

[22] F. Sun, B.X. Long, Rational Reflection and Localization Construction of Flipped Classroom, [J]e-Education Research, 2015(9), 83-88.(In Chinese) 